\title{
FEM METHOD WITH THE USE OF TREFFTZ FUNCTIONS FOR DETERMINATION OF HEAT TRANSFER COEFFICIENT IN A MINICHANNEL
}

\begin{abstract}
Magdalena PIASECKA ${ }^{1}$, Beata MACIEJEWSKA ${ }^{2}$
Abstract: The paper presents the FEM method for determination of boiling heat transfer coefficient in cooling liquid flow in a rectangular minichannel with asymmetric heating. Experimental research has focused on the transition from single phase forced convection to nucleate boiling, i.e. the zone of boiling incipience. The "boiling front" location has been determined from the temperature distribution of the heated wall obtained from liquid crystal thermography. The main part of the test section has been a minichannel of pre-set depth from 0.7 to 2.0 $\mathrm{mm}$, of different spatial orientations. Local values of heat transfer coefficient have been determined following the solution of the two-dimensional inverse heat transfer problem. This problem has been solved with the use of Trefftz functions. Trefftz functions have been used to construct base functions in the finite element method (FEMT).
\end{abstract}

\section{NOMENCLATURE}

$A, a, b \quad$ - linear combination coefficient,

$[A],[T],[V],[v]$ - matrices,

I - error functional,

$J \quad-$ number of elements,

$L \quad$ - minichannel length, $\mathrm{m}$,

lw - number of nodes in an element,

$M, N \quad$ - number of Trefftz functions used for approximation,

$P \quad$ - number of measurement points,

BI - boiling incipience,

$q_{V} \quad$ - volumetric heat flux (capacity of internal heat source), $\mathrm{W} / \mathrm{m}^{3}$,

$T \quad$ - temperature, $\mathrm{K}$,

$\widetilde{T}(x, y)$ - temperature approximate, $\mathrm{k}$,

$u(x, y)$ - particular solution of the non-homogeneous equation,

$v(x, y)$ - Trefftz functions,

$x, y \quad$ - spatial coordinates,

\footnotetext{
${ }^{1}$ Kielce University of Technology, Faculty of Mechatronics and Machine Building, Chair of Mechanics, al. 1000-lecia P.P.7, 25-314 Poland; email: tmpmj@tu.kielce.pl

${ }^{2}$ Kielce University of Technology, Faculty of Management and Computer Modelling, Chair of Mathematics, al. 1000-lecia P.P.7, 25-314 Poland; email: beatam@tu.kielce.pl
} 


\section{Greek letters}

$\begin{array}{ll}\Omega & \text { - flat domain, } \\ \alpha & \text { - heat transfer coefficient, } \mathrm{W} /\left(\mathrm{m}^{2} \mathrm{~K}\right), \\ \delta & \text { - depth, } \mathrm{m}, \\ \varphi(x, y) & \text { - base functions, } \\ \lambda & \text { - thermal conductivity, } \mathrm{W} /(\mathrm{mK}), \\ & \\ c & \text { - fluid, } \\ F & \text { - foil, } \\ G & \text { - glass, } \\ i, j, k, n & \text { - numbers, } \\ p & \text { - measurement point. }\end{array}$

\section{Indexes}

\section{INTRODUCTION}

Mini heat exchangers are used to provide higher cooling capacity for new technologies. This means a reduction in their size and cost but identical power. Owing to the change of state, which accompanies flow boiling in minichannels, it is possible to meet contradictory demands simultaneously, i.e. to obtain a heat flux as large as possible at small temperature difference between the heating surface and the saturated liquid and, at the same time, retain small dimensions of heat transfer systems.

\section{MAIN GOAL}

The objectives of the experimental investigations and calculations discussed in the present article are evaluation of a heat transfer model and numerical approach to solving the inverse boundary problem, and calculation of local heat transfer coefficient using FEM method with Trefftz functions. The application of liquid crystal thermography enables determination of two-dimensional temperature distribution on the heating surface.

\section{EXPERIMENTAL SET-UP}

The essential part is the test section with a minichannel (Fig. 1a, \#4) of pre-set depth: 0,$7 ; 1,1.5$ or $2 \mathrm{~mm}, 40 \mathrm{~mm}$ width and $360 \mathrm{~mm}$ length, which has different inclination angle with respect to the horizontal line (spatial orientations of the test section are from vertical to horizontal with $30 \%$ inclination angle adjustment) [4]. The heating element for working fluid (R 123, R 11 or FC 72), which flows along the minichannel is an alloy foil (\#3) stretched between the front cover (\#6) and the channel body (\#7). The heating element $0.1 \mathrm{~mm}$ foil designated as Haynes-230, made of $\mathrm{Ni}-\mathrm{Cr}-\mathrm{W}$-Mo high-temperature alloy is selected. It is possible to observe changes in the foil surface temperature through the opening covered with glass (\#1). One side of the heating foil (between the foil and the glass) is covered with a base coat and liquid crystal paint (\#2). The test section body (\#7) contains channels, to which water is fed (\#5), or which are air gaps. On the surface of the quasiadiabatic wall (\#7) constant temperature is maintained (the arithmetic mean 
of the temperatures at the inlet and outlet of the minichannel). In the inlet channel and the outlet chamber pressure converters are installed. The liquid temperature is measured at the inlet and at the outlet of the minichannel. The main loop (Fig. 1b), besides the test section consists of the following elements: \#21 - a rotary pump, \#19, \#22, \#24 - heat exchangers and \#20 - compensating tank. The most important set-up elements for the flow, pressure and temperature control and measurement are the inverter (\#25), rotameters (\#23), pressure converters and thermocouples (\#10).

a)

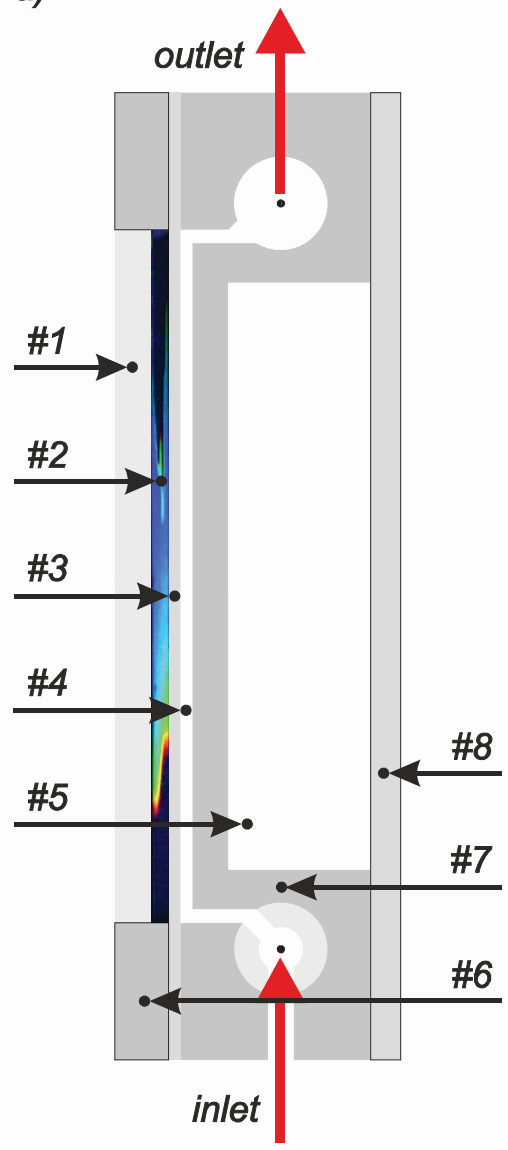

b)

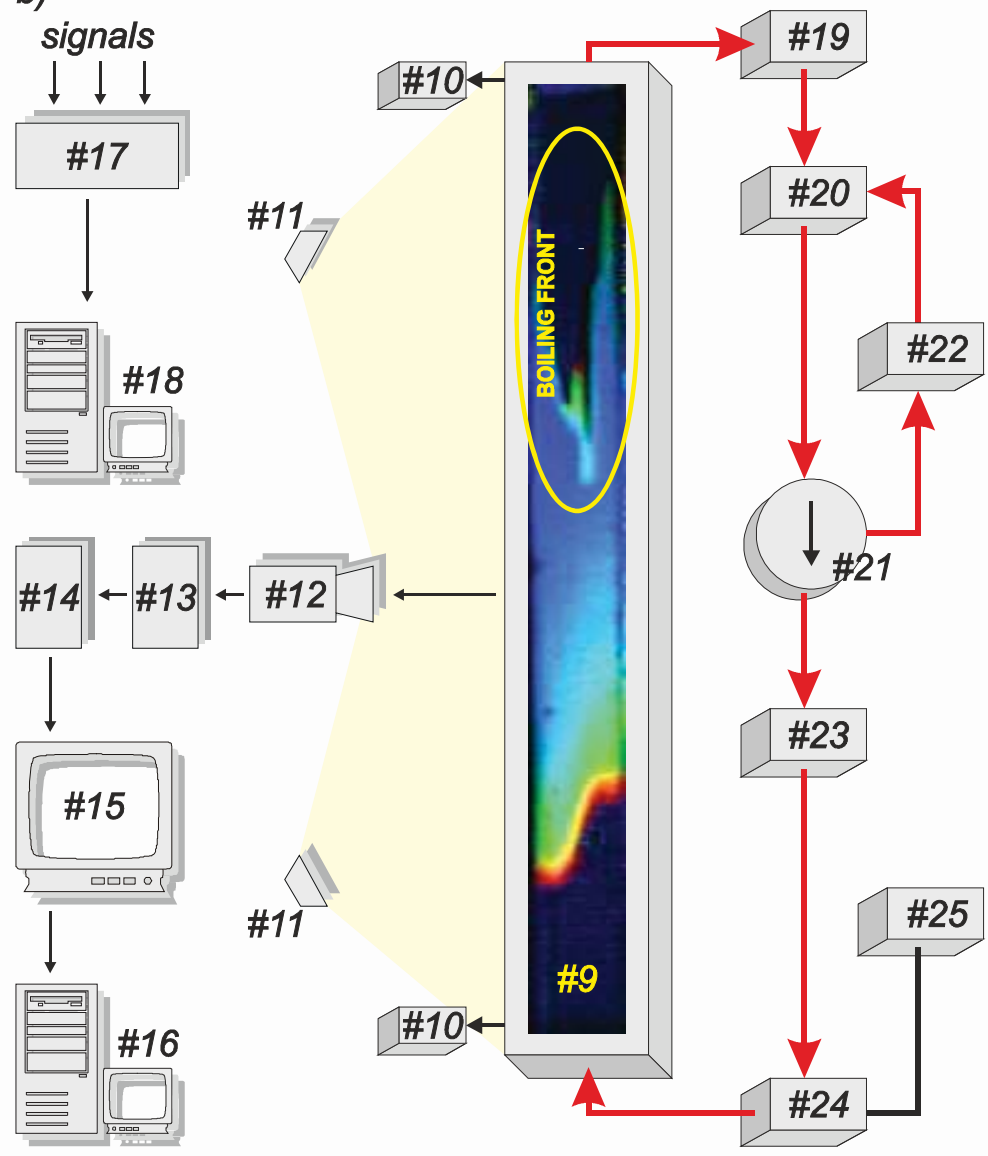

Figure 1. Diagrams of a) the test section: \#1-glass, \#2-liquid crystals, \#3-heating foil, \#4-minichannel, \#5-rear cover, \#6-front cover, \#7-channel body (quasiadiabatic wall), \#8-rear cover, b) the main loop of the flow system and the data and color image acquisition system: \#9-test section, \#10-pressure converter and thermocouple, \#11-lighting system, \#12-CCD video camera, \#13-RGB signal decomposer, \#14-Betacam recorder, \#15-monitor, \#16-computer with frame grabber and monitor, \#17-data acquisition station, \# 18-computer with monitor, \#19,\#22,\#24-heat exchanger, \#20-compensating tank, \#21-rotary pump, \#23-rotameters, \# 25-inverter 
The use of thermography has been made possible thanks to the color image acquisition system, Fig. 1b, which includes \#12 - CCD video camera with \#13 - RGB signal decomposer, \#14 - Betacam recorder with \#15 - monitor and \#16 - computer with frame grabber, monitor and specialist software. The registration of the remaining measurement data is carried out with data acquisition station Keithley 500 A - \#17, equipped with ViewDac software installed at another computer - \#18.

When the refrigerant flows along the minichannel, an increase in the electric power supplied to the heating foil causes boiling incipience in the minichannel. This is observed as a "boiling front", which moves upstream together with an increase in the heat flux [2-4]. The "boiling front" is identified as a sudden drop in the temperature of the heating surface following its rise, at constant capacity of the internal heat source. The observation of the two-dimensional temperature distribution on the heating surface of the minichannel is possible owing to liquid crystal thermography. A calibration procedure has to precede the virtual boiling heat transfer investigation. Its aim is to assign corresponding temperature values to the hues observed on the surface covered with liquid crystals [5].

\section{TWO-DIMENSIONAL MODEL}

\subsection{PROBLEM FORMULATION}

In a two-dimensional approximation of heat flow through major elements of the test section (Fig. 2), there occurs a simple problem in the glass barrier and an inverse problem in the heating foil $[2,3]$. To solve them, temperature measurements in the foil on the glass-side boundary, obtained thanks to the application of liquid crystal thermography, are used. When solving the inverse problem (no boundary condition on the boundary $y=\delta_{G}+\delta_{F}$ ), the temperature field and heat flux density in the foil on the boundary $y=\delta_{G}+\delta_{F}$ are determined. Local values of heat transfer coefficient are calculated with the assumption of linear temperature distribution of the liquid flowing along the minichannel (liquid measurement at minichannel inlet/outlet). It is assumed that in the foil operates a heat source of constant efficiency $q_{V}$, distributed evenly in the entire volume of the foil.

The temperature of the glass barrier $T_{G}(x, y)$ satisfies the equation:

$$
\nabla^{2} T_{G}=0
$$

where $(x, y) \in \Omega_{G}=\left\{(x, y) \in R^{2}: 0<x<L, \quad 0<y<\delta_{G}\right\}$,

The temperature of the heating foil $T_{F}(x, y)$ satisfies the equation:

$$
\nabla^{2} T_{F}=-\frac{q_{V}}{\lambda_{F}}
$$


where $(x, y) \in \Omega_{F}=\left\{(x, y) \in R^{2}: x_{1}<x<x_{P}, \quad \delta_{G}<y<\delta_{G}+\delta_{F}\right\}, x_{1}$ is the coordinate of the first temperature measurement, $x_{P}$ is the coordinate of the final temperature measurement.

Moreover, for $y=\delta_{G}$ and $0 \leq x \leq L$ (the foil-glass boundary), the following conditions have been assumed:

$$
\begin{aligned}
T_{F}\left(x_{p}, \delta_{G}\right)= & T_{G}\left(x_{p}, \delta_{G}\right)=T_{p} \text { for } p=1,2, \ldots P \\
& T_{F}\left(x, \delta_{G}\right)=T_{G}\left(x, \delta_{G}\right) \\
& -\lambda_{F} \frac{\partial T_{F}}{\partial y}=-\lambda_{G} \frac{\partial T_{G}}{\partial y}
\end{aligned}
$$

for $p=1,2, \ldots, P$.

Conditions on other boundaries:

$$
\begin{gathered}
\frac{\partial T_{G}}{\partial y}=0 \text { for } y=0 \text { and } 0<x<L \\
\frac{\partial T_{G}}{\partial x}=0 \text { for } x=0 \text { as well as } x=L \text { and } 0<y<\delta_{G} \\
T_{F}\left(x_{1}, y\right)=T_{1} \text { for } \delta_{G}<y<\delta_{G}+\delta_{F} \\
T_{F}\left(x_{P}, y\right)=T_{P} \text { for } \delta_{G}<y<\delta_{G}+\delta_{F}
\end{gathered}
$$

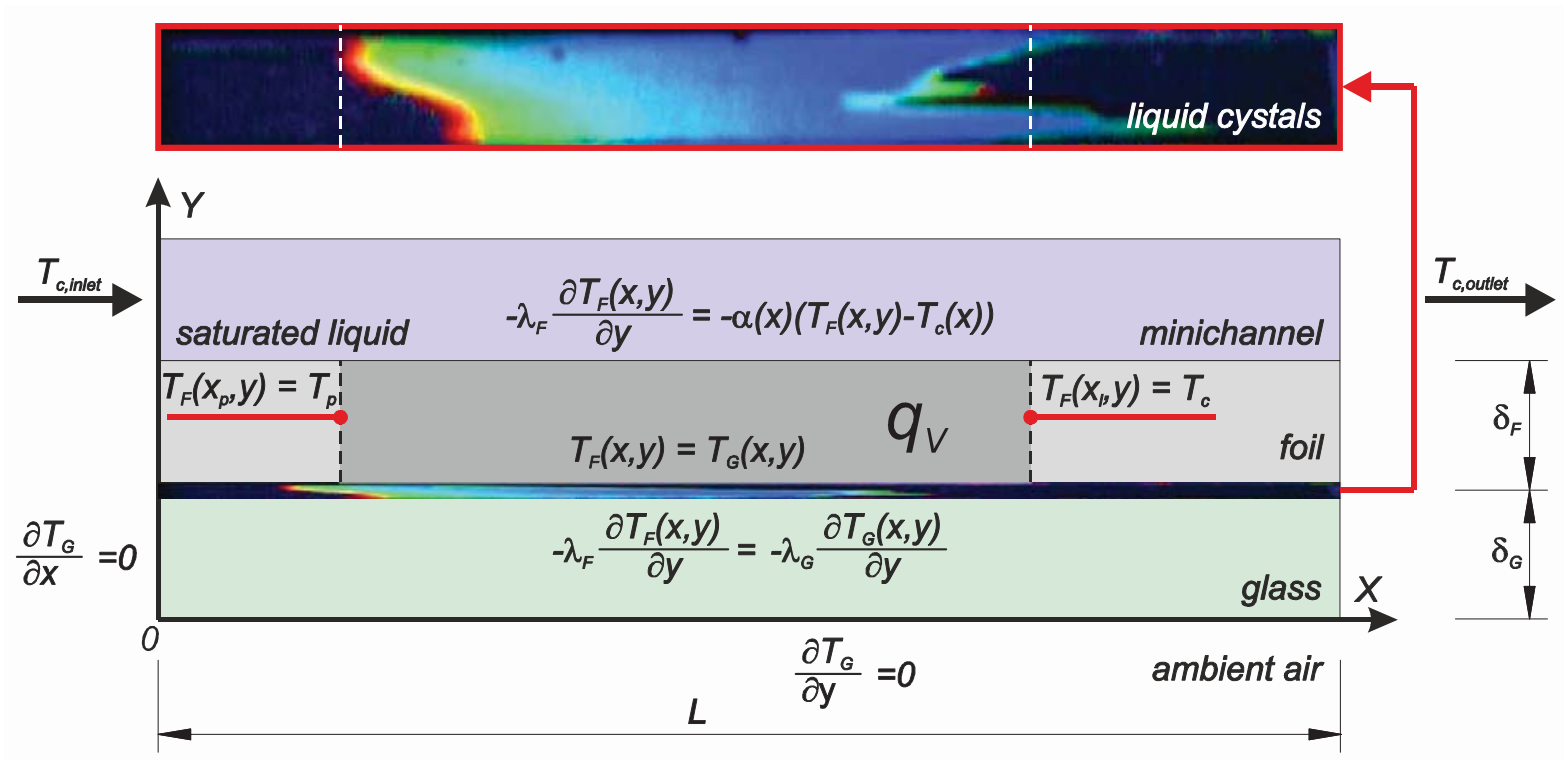

Figure 2. Boundary conditions for a two-dimensional approximation of heat flux across main elements of the test section 
The problem thus formulated is solved by means of Trefftz functions ( $T$-functions) [1]. These functions are used to solve both simple and the inverse problems. The basic property of Trefftz functions is satisfying the governing equation. In the problem under discussion, it is the Laplace equation (1). What remains to be done is to adjust the linear combination of Trefftz functions to required initial and boundary conditions, and - in the case of inverse problems - also to the measurements, e.g. temperature.

In order to determine the value of heat transfer coefficient on the boundary $y=\delta_{G}+\delta_{F}$, the temperature of the glass barrier $T_{G}\left(x, \delta_{G}\right)$ is first determined from the solution of a simple problem, and subsequently the foil temperature $T_{F}\left(x, \delta_{G}\right)$ is determined from the solution of the inverse problem. Knowing the foil temperature distribution enables the determination of local values of heat transfer coefficient on the heating foil-liquid boundary in the minichannel from the condition:

$$
-\lambda_{F} \frac{\partial T_{F}\left(x, \delta_{G}+\delta_{F}\right)}{\partial y}=\alpha(x)\left(T_{F}\left(x, \delta_{G}+\delta_{F}\right)-T_{c}(x)\right)
$$

where $\alpha$ is the sought heat transfer coefficient, and $T_{c}(x)$ is liquid temperature, approximated linearly along the entire minichannel length.

\subsection{FINITE ELEMENT METHOD WITH THE USE OF T- FUNCTIONS (FEMT)}

The solution method for Eqs. (1) and (2) is a generalisation of the method presented in [1]. In order to solve the formulated problem, domains $\Omega_{G}$ and $\Omega_{F}$ are divided into elements $\Omega_{G}^{j}$ and $\Omega_{F}^{j}$. The approximate solution of Eq. (1) in each of the elements $\Omega_{G}^{j}$ is a linear combination of Trefftz functions:

$$
\widetilde{T}_{G}^{j}(x, y)=\sum_{n=1}^{N} A_{j n} v_{n}(x, y)
$$

With the assumption that the temperatures $\widetilde{T}_{G}^{j k}$ at the nodes $\left(x_{k}, y_{k}\right)$ of the element $\Omega_{G}^{j}$ are known, coefficients $A_{j n}$ are calculated from the linear systems of equations

$$
\widetilde{T}_{G}^{j}\left(x_{k}, y_{k}\right)=\widetilde{T}_{G}^{j k}=\sum_{n=1}^{N} A_{j n} v_{n}\left(x_{k}, y_{k}\right), \quad k=1,2, \ldots . N
$$

In the abbreviated version, Eqs. (11) take the form $[v][A]=[T]$, whence upon inverting the matrix $[v],[A]=[v]^{-1}[T]=[V][T]$ is obtained. Therefore,

$$
A_{j n}=\sum_{k=1}^{N} V_{n k} \widetilde{T}_{G}^{j k}
$$

Substituting (12) into (10), base functions for the element $\Omega_{G}^{j}$ are obtained in the following form: 


$$
\varphi_{j k}(x, y)=\sum_{n=1}^{N} V_{n k} v_{n}(x, y)
$$

These functions strictly satisfy Eq. (1). Temperature in each element $\Omega_{G}^{j}$ is shown as a linear combination of base functions $\varphi_{j k}(x, y)$ :

$$
\widetilde{T}_{G}^{j}(x, y)=\sum_{k=1}^{l w} \varphi_{j k}(x, y) \widetilde{T}_{G}^{n}
$$

where $j$ is the number of the element, $k$ is the number of the node in the $j$ th element, $n$ is the number of the node in the entire domain $\Omega_{G}, I W$ is the number of nodes in the element. The unknown coefficients $\widetilde{T}_{G}^{n}$ of the linear combination (14) are determined by minimization of the functional $J$ :

$$
\begin{aligned}
& J=\int_{0}^{\sigma_{G}}\left(\frac{\partial \widetilde{T}_{G}^{1}}{\partial x}(0, y)\right)^{2} d y+\int_{0}^{\delta_{G}}\left(\frac{\partial \widetilde{T}_{G}^{J}}{\partial x}(L, y)\right)^{2} d y+\sum_{p_{j}=1}^{P}\left(\widetilde{T}_{G}^{j}\left(x, \delta_{G}\right)-T_{p_{j}}\right)^{2}+ \\
& +\sum_{j=1}^{L 1} \int_{x_{j-1}}^{x_{j}}\left(\frac{\partial \widetilde{T}_{G}^{j}}{\partial y}(x, 0)\right)^{2} d x+\sum_{i=0}^{: L 2-1} \sum_{j=1}^{L 1-1} \int_{y_{i}}^{y_{i+1}}\left(\widetilde{T}_{G}^{j+i^{*} L 1}\left(x_{j}, y\right)-\widetilde{T}_{G}^{j+1+i^{*} L 1}\left(x_{j}, y\right)\right)^{2} d y+ \\
& +\sum_{i=0}^{: L 2-1} \sum_{j=1}^{L 1-1} \int_{y_{i}}^{y_{i+1}}\left(\frac{\partial \widetilde{T}_{G}^{j+i^{*} L 1}}{\partial x}\left(x_{j}, y\right)-\frac{\partial \widetilde{T}_{G}^{j+1+i^{*} L 1}}{\partial x}\left(x_{j}, y\right)\right)^{2} d y+ \\
& +\sum_{j=0}^{: L 1-1} \sum_{i=1}^{L 2-1} \int_{x_{j}}^{x_{j+1}}\left(\widetilde{T}_{G}^{i+j^{*} L 2}\left(x, y_{i}\right)-\widetilde{T}_{G}^{i+1+j^{*} L 2}\left(x, y_{i}\right)\right)^{2} d x+ \\
& +\sum_{j=0}^{: L 1-1} \sum_{i=1}^{L 2-1} \int_{x_{j}}^{x_{j+1}}\left(\frac{\partial \widetilde{T}_{G}^{i+1+j^{*} L 2}}{\partial y}\left(x, y_{i}\right)-\frac{\partial \widetilde{T}_{G}^{i+1+j^{*} L 2}}{\partial y}\left(x, y_{i}\right)\right)^{2} d x
\end{aligned}
$$

where L1 is the number of elements in the Ox axis direction, L2 is the number of elements in the Oy axis direction.

In a similar way, foil temperature is determined. In each element $\Omega_{F}^{j}$, it is presented in the form of a linear combination of base functions $\varphi_{j k}(x, y)$ defined by the formula (13):

$$
\widetilde{T}_{F}^{j}(x, y)=u(x, y)+\sum_{k=1}^{l w} \varphi_{j k}(x, y)\left(\widetilde{T}_{F}^{n}-u\left(x_{n}, y_{n}\right)\right)
$$

where $n$ is the number of the node in the entire domain $\Omega_{F}, u\left(x_{n}, y_{n}\right)$ is the value of the particular solution in the $n$th node of the domain $\Omega_{F}$, while $j, k$ and Iw carry the same meaning as in the formula (14). The unknown coefficients $\widetilde{T}_{F}^{n}$ of the linear combination (16) are determined by minimization of the appropriate functional, structured according to the principle similar to that of the functional (15). 


\section{RESULTS}

Boiling incipience is recognised as a sudden drop in the heating surface temperature that follows its systematic increase, at constant capacity of the internal heat source. It is called "boiling front" and it shifts in the direction opposite to the liquid flow in the minichannel with the increase in the heat flux supplied to the heating surface [2-5]. Fig. 3 shows examples of hue distribution on the foil surface, obtained with liquid crystal thermography, with a visible "boiling front" (BI).

FEMT has used four $T$-functions: $1, x, y, x y$. In the domains $\Omega_{G}$ and $\Omega_{F}$, a rectangular mesh, parallel to the coordinate system axis, has been introduced. The domain $\Omega_{G}$ has been divided into 2849 elements, $\Omega_{F}$ - into from 651 to 1169 elements. In the domain $\Omega_{G} 3264$ nodes have been placed, in the domain $\Omega_{F}$ - from 1304 to 2340 nodes. In each element $\Omega_{G}^{j}, \Omega_{F}^{j}$ a set of four nodes placed in the vertices of the rectangular element has been selected. The function $u(x, y)=-0,5 q_{V} \lambda_{F}^{-1} y^{2}$ has been assumed to be the particular solution of Eq. (2). Local heat transfer coefficients as a function of the distance from the inlet to the minichannel have been presented in Fig. 4.

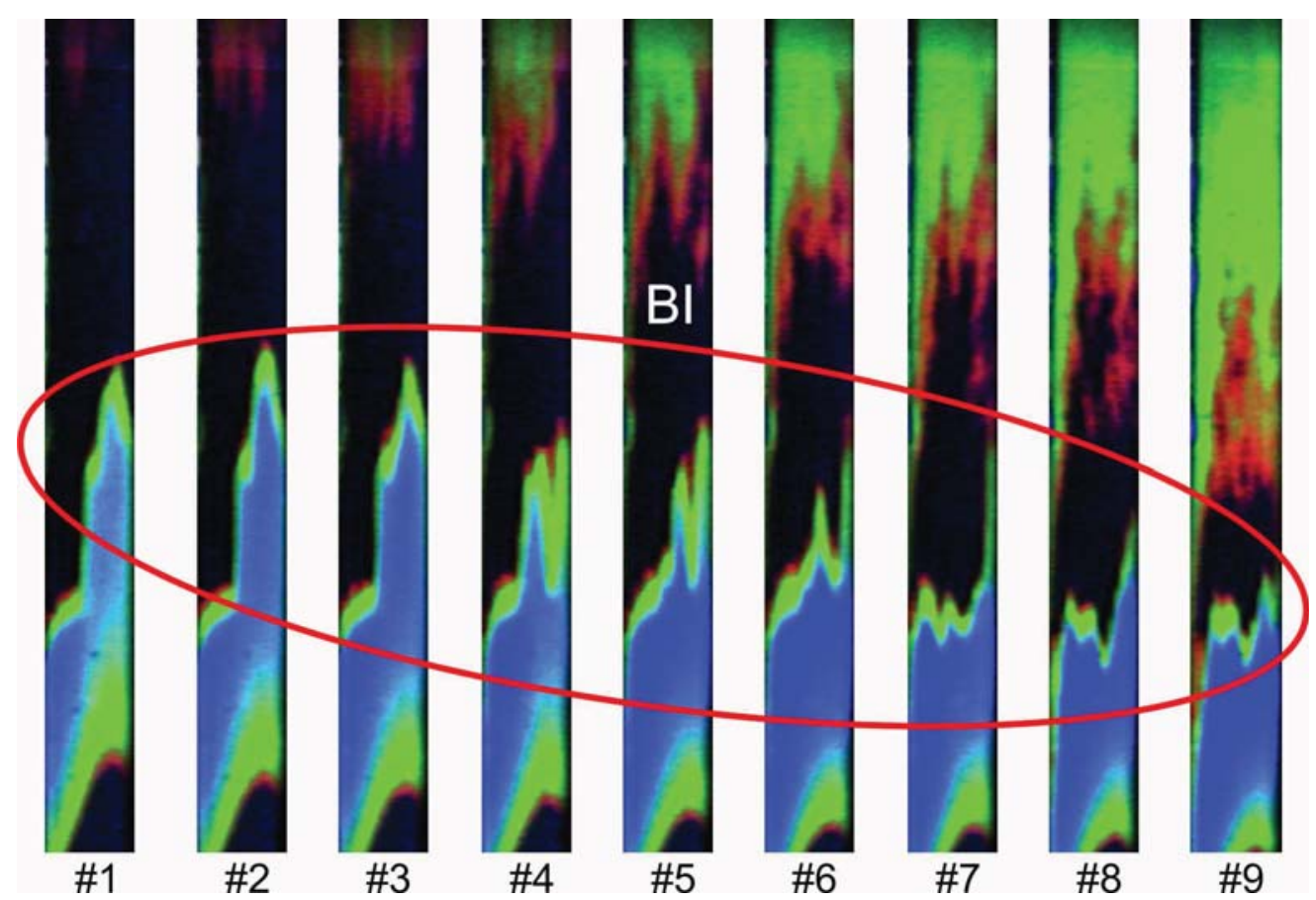

Figure 3. Images of temperature distribution on the heating wall, experimental data: minichannel depth $1 \mathrm{~mm}$, vertical channel, boiling liquid $R$ 123, flow velocity $0.35 \mathrm{~m} / \mathrm{s}$, mass flux $220 \mathrm{~kg} /\left(\mathrm{m}^{2} \mathrm{~s}\right)$, pressure at the channel inlet $340 \mathrm{kPa}, \mathrm{q}_{\mathrm{v}}=2.5 \cdot 10^{5} \div 3.7 \cdot 10^{5} \mathrm{~kW} / \mathrm{m}^{3}$ 


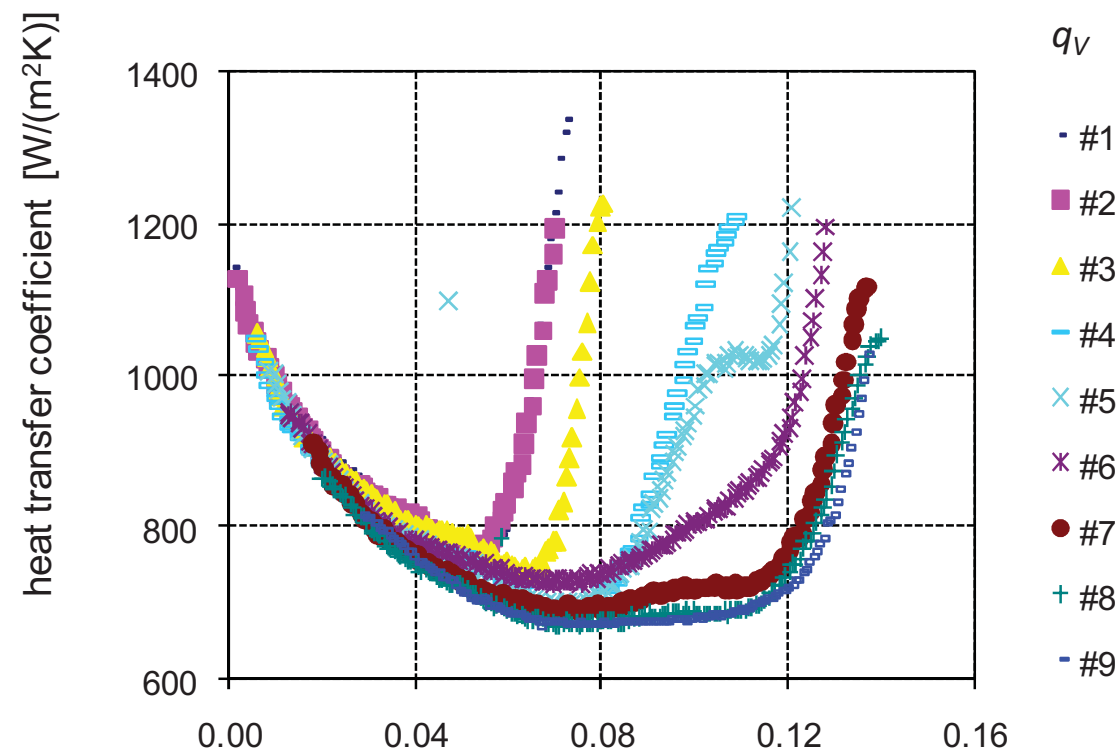

distance form the minichannel inlet $x[\mathrm{~m}]$

Figure 4. Heat transfer coefficient dependence on the distance along the minichannel length

\section{CONCLUSIONS}

In the minichannel flow boiling, considerable heat transfer enhancement takes place at boiling incipience. It is observed as a sharp increase in the heat transfer coefficient. Boiling incipience was observed as the "boiling front" moving upstream when the heat flux density increased. It is accompanied by the occurrence of "nucleation hysteresis" phenomenon. It involves a considerable heating surface temperature drop.

The determined approximates of the glass barrier and heating foil temperatures strictly satisfy the respective differential equations (1) and (2). In the FEMT method, the condition (3a) is strictly satisfied (element nodes are placed at measurement points), while the remaining boundary conditions are approximately satisfied.

\section{ACKNOWLEDGEMENTS}

The research has been financially supported by the Polish Ministry of Science and Higher Education, Grant No. N N512 354037 for the years 2009-2012.

\section{REFERENCES}

[1] Cialkowski M., Frackowiak A.: Funkcje cieplne i ich zastosowanie do rozwiązywania zagadnień przewodzenia ciepła i mechaniki (in Polish), WPP, Poznań 2000. 
[2] Hozejowska S., Piasecka M., Poniewski M. E.: Boiling heat transfer in vertical minichannels. Liquid crystal experiments and numerical investigations, Int.J. of Thermal Sciences, 48, No. 6 (2009), pp. 1049-1059.

[3] Piasecka M., Hozejowska S., Poniewski M. E.: Experimental evaluation of flow boiling incipience of subcooled fluid in a narrow channel, Int. J. of Heat and Fluid Flow, 25 (2004), pp. 159-172.

[4] Piasecka M.: Experimental investigation on flow boiling heat transfer in minichannels of different spatial orientations, Proc. Of the Int. Conf. Experimental Fluid Mechanics 2009, 25-27 XI.2009, Liberec, pp. 290-303.

[5] Piasecka M., Poniewski M.E.: Liquid crystal thermography applied to investigations into heat transfer in minichanels, Metrology and Measurement Systems, 11, No.3 (2004), pp. 259-274. 